\author{
PROCEEDINGS OF THE NUTRITION SOCIETY \\ A Scientific Meeting was held at the University of Nottingham on 12-15 July 1993
}

\title{
Keynote Lecture 1
}

\section{The application of nutritional science to clinical practice}

\author{
B Y M. ELIA \\ Dunn Clinical Nutrition Centre, Hills Road, Cambridge CB2 $2 \mathrm{DH}$
}

\begin{abstract}
Nutritional science consists of multiple overlapping disciplines: agricultural science including animal husbandry; food science; public health; nutritional physiology; and therapeutic or clinical nutrition. The application of nutritional science to clinical practice has undoubtedly resulted in improved survival and improved quality of life in certain groups of patients. It has also resulted in new concepts that are not only of fundamental importance to physiology and human biology, but also to the development of new therapeutic strategies. Several of these new concepts have arisen from three interrelated areas that are essentially unique to human and veterinary clinical nutrition. These are: (1) the consequences of bypassing the gut, which occurs during intravenous nutrition; (2) the effects of administering nutrients in quantities and proportions that are not normally possible with normal diets; (3) the effects of using continuous feeding over $24 \mathrm{~h}$ rather than intermittent feeding.
\end{abstract}

\section{BYPASSING THE GUT}

\section{Bacteriological, metabolic and clinical consequences}

Mammals have evolved complex biochemical, immunological and mechanical defence systems that are located at the interfaces between the external environment and their own tissues, i.e. the integument, the gastrointestinal tract and the respiratory tract. The administration of feeds directly into central veins bypasses all these defences, making infection much more likely. Indeed, in the early 1970s, just a few years after the first successful use of prolonged parenteral nutrition in man (Dudrick et al. 1968) was hailed as one of the most important advances in nutritional support for decades, serious infections, mainly in the form of catheter-related sepsis, became a major problem. Catheter-related sepsis occurred in as many as $25-30 \%$ of patients being fed parenterally. In the late 1970 s the incidence of catheter-related sepsis was reduced to about $5 \%$ in many centres, because the central line came to be regarded as a 'lifeline' for administration of feed only and not for the convenience of administering blood products, drugs and fluids, or for withdrawing blood, especially by individuals not employing strict aseptic techniques. In the 1980 s the incidence of catheter-related sepsis was reduced further to about $3 \%$ through the use of polyurethane catheters which replaced the older more 'adhesive' and thrombogenic polyvinyl catheters which were more likely to predispose to bacterial seeding. In the 1990 s new catheters coated with silver sulpha- 
diazine have become commercially available in an attempt to reduce the incidence of catheter-related sepsis even further. However, their value still remains to be proven, especially since there is concern about the development of antibiotic resistance by bacteria. In general, the introduction of nutrition teams (Elia, 1993) has probably been the most important factor in reducing the incidence of catheter-related sepsis, emphasizing the value of implementing strict protocols that employ aseptic techniques.

A different concept relating to the infectious complications of parenteral nutrition was that the parenteral nutrition might act as a form of iatrogenic immunosuppression (Alverdy \& Burke, 1992), a possibility raised in 1970 (Boeckman \& Krill, 1970). Several years later (Dionigi et al. 1977) it was noted that intravenous nutritional support in malnourished dogs could restore body composition and restore a number of immunological abnormalities, but it could not restore to normal some of the lymphocyte function tests. In the $1980 \mathrm{~s}$ a series of studies involving septic models of injury reported that parenteral nutrition modified the metabolic response to sepsis and adversely affected outcome.

Peterson et al. (1981) and Kudsk et al. (1981) reported that the mortality of orally-fed depleted rats suffering from experimentally-induced Escherichia coli peritonitis was about $50 \%$, in contrast to a mortality of more than $90 \%(P<0.01)$ in depleted rats given parenteral nutrition for 1 week before the peritonitis. Similar results were reported later in normal rats (Kudsk et al. 1983). Normally-nourished rats fed by gastrostomy had about $40 \%$ mortality $2 \mathrm{~d}$ after $E$. coli peritonitis, whilst those fed by parenteral nutrition for 1 week before the peritonitis had about $80 \%$ mortality.

Saito et al. (1987) complemented the previously described observations by demonstrating that in rats the metabolic response to $30 \%$ burns was exaggerated in parenterally-fed rats compared with gastrostomy-fed rats. Thus, the plasma cortisol and glucagon concentrations and urinary vanillyl mandelic acid (VMA) excretion were substantially greater in those fed parenterally, from day 1 through to day 14 after the burn. Human studies also complemented the previously described observations (Fong et al. 1989; Lowry, 1990). In the study of Fong et al. (1989) normal subjects were fed either orally or intravenously for a period of 1 week before being challenged with an intravenous dose of endotoxin. The subjects fed parenterally had a greater stress hormone response (cortisol, adrenaline), a greater acute-phase protein response (C reactive protein), which is used as an index of the severity of injury response, and a greater cytokine (TNF) response.

In clinical practice morbidity is a more important outcome variable than biochemical variables. Clinical trials attempting to assess outcome are often difficult to interpret, especially in heterogenous groups of critically ill patients who are treated in different ways. Nevertheless, there is some evidence that parenterally-fed patients suffering from the effects of abdominal injury and laparotomy have a greater risk of developing septic complications (e.g. abdominal abscess, pneumonia) than those fed enterally. Apart from one small study (Adams et al. 1986), which reported no advantage of enteral over parenteral feeding, there is remarkable consistency in the results of three other studies, in that the incidence of septic complications was two- to tenfold lower in patients fed enterally than those fed parenterally (Moore \& Jones, 1986; Moore \& Moore, 1991; Kudsk et al. 1992; Moore et al. 1992). This effect seemed to be independent of the presence or absence of catheter sepsis, as shown by the largest and most recent study ( $n$ 235) which was essentially a meta-analysis of eight smaller studies (Moore et al. 1992), 
and by the study of Kudsk et al. (1992) which analysed the incidence of individual septic complications (abscess, pneumonia, catheter-related sepsis). Although criticisms can be raised against individual studies, all the results taken together suggest an advantage of enteral nutrition over parenteral nutrition at least in subjects who have sustained abdominal injuries and have had a laparotomy.

If this conclusion is accepted there is a need to establish a mechanism by which enteral nutrition protects against sepsis. About 85 years ago Eli Metchnikoff (1908), the father of the phagocytic theory of immunity, suggested that the passage of bacteria and toxins from the gastrointestinal tract into the body (translocation) was an important cause of morbidity and premature death. Today translocation has become a prominent area of research in clinical nutrition. The barrier that keeps bacteria and toxins in the lumen of the gastrointestinal tract appears to break down after a variety of systemic insults (burn, trauma, haemorrhage, endotoxin; Border et al. 1987; Alverdy et al. 1988; Inoue et al. 1989; Alexander, 1990; Dietch et al. 1990; Dietch, 1992; Fukushima et al. 1992; Troche, 1993), especially if there is associated protein malnutrition. This means that bacteria and toxins pass to the mesenteric nodes and subsequently to the blood and other organs causing septicaemia and abscesses. Under normal circumstances mesenteric lymph nodes from guinea-pigs are essentially sterile, but $24-48 \mathrm{~h}$ after severe injury, e.g. $50 \%$ burns, most of them can become culture positive with intestinal organisms (Inoue et al. 1989). A proportion of bacteria escape the mesenteric lymph nodes, to find their way into the blood (septicaemia) and a variety of organs (where they may cause abscesses). Translocation is also enhanced by parenteral nutrition. In the study of Alverdy et al. (1988) about two-thirds of mesenteric lymph nodes from rats fed parenterally were culture positive compared with none in those given a normal oral diet. Other studies (see Troche, 1993) have confirmed that parenteral nutrition increases bacterial 'translocation' to the mesenteric nodes of rats.

The cause of the increased 'translocation' during parenteral nutrition is uncertain (Alverdy \& Burke, 1992), but a number of processes have been implicated. The absence of luminal nutrition causes the following: decreased production of mucous, which acts as a barrier to bacterial penetration across mucous membranes (Parsons et al. 1979); decreased secretion into the lumen of the gut of immunoglobulin $\mathrm{A}(\operatorname{IgA})$, which binds to bacteria (Alverdy et al. 1985); decreased secretion of bile, which is not only the major source of intestinal IgA in the rat (Jones, 1984) but also the source of bile acids which may bind to endotoxin to prevent its translocation. In addition 'bowel rest' may decrease peristalsis, which favours bacterial overgrowth. The absence of luminal nutrition also causes mucosal atrophy, loss of gut-associated lymphocytes, and reduced blood flow, all of which may be important in the translocation process.

Apart from translocation, other factors can be suggested to explain the increased incidence of septic complication in the subjects receiving parenteral nutrition after abdominal injury and laparotomy. It is possible that the parenteral nutrition mixtures may be lacking in some immunomodulatory nutrient that is normally present in oral diets (see p. 7). Alternatively, since in some of the clinical studies there was a tendency for more nutrients to be administered during parenteral nutrition than during enteral tube feeding, it can be postulated that excess administration was responsible for the increased incidence of infection. For example, in the study of Moore et al. (1992) the excess administration of intravenous nutrition compared with enteral nutrition was associated with greater hyperglycaemia, which predisposes to infection and bacterial proliferation. 
The high incidence of pneumonia during parenteral nutrition in some of the previously mentioned clinical studies may be due to aspiration of bacteria from the upper gastrointestinal tract, especially since lack of peristalsis and lack of upper gastrointestinal tract secretions favour bacterial overgrowth, which is common in critically-ill patients (Moulin et al. 1982).

Although there is some uncertainty about which of the mechanisms predominates, several of the previously mentioned observations on sepsis rates have reinforced the old adage that the gastrointestinal tract should be used for feeding whenever it is available, and that parenteral nutrition should only be used when the gut is not available. In some centres there has been a trend in providing small and tolerable amounts of enteral nutrition to parenterally-fed patients, based on the belief that a small or even minimal amount of enteral feeding is sufficient to maintain gastrointestinal integrity and provide mucosal protection (Lucas et al. 1986; Elia et al. 1987; Inoue et al. 1989).

\section{Effect on trace element requirements and toxicity}

Apart from microbiological protection, the gastrointestinal tract provides protection against toxicity from a variety of substances that may be present in the diet, including protection against the toxicity of some trace elements. For some trace elements, such as $\mathrm{Se}, \mathrm{F}$ and $\mathrm{I}$, there is little, if any, regulation over absorption. The absorption of these trace elements is almost complete $(\geq 80 \%)$ irrespective of dietary intake over a wide range. For other trace elements such as $\mathrm{Zn}, \mathrm{Cu}, \mathrm{Fe}$ and $\mathrm{Mn}$, which have a lower and more variable fractional absorption, there are important regulatory intestinal processes that prevent excessive uptake when their dietary intake is excessive. Indeed, for some trace elements such as Fe (McCance \& Widdowson, 1943) the gut essentially provides the only defence against excess accumulation within the body. There is no effective way of disposing of excess Fe once it has entered the body, e.g. by repeated blood transfusions or in patients with haemochromatosis, who have an intestinal defect leading to increased $\mathrm{Fe}$ absorption. The Fe progressively accumulates within tissues until clinical symptoms occur (e.g. cirrhosis, bronze diabetes and infertility which are all features of haemochromatosis).

When it comes to parenteral nutrition it is important to remember that the recommended intake of trace elements may be substantially lower than that for normal oral intake (Elia, 1990), particularly for those trace elements such as $\mathrm{Cr}$ and $\mathrm{Mn}$ that are normally absorbed to the extent of less than 5\% ( $\mathrm{Cr}<3 \%$, Mn 3-4\%; National Academy of Sciences, 1980, 1989). If these considerations are ignored potential problems may arise. For example, since the normal intake of $\mathrm{Mn}$ is about $4 \mathrm{mg}(80 \mu \mathrm{mol}) / \mathrm{d}$ (National Academy of Sciences, 1989; Department of Health, 1991) and its absorption is 3-4\% (Greenberg et al. 1943), it can be calculated that the amount required for intravenous nutrition is only $120-150 \mu \mathrm{g}$ (about $3 \mu \mathrm{mol}$ )/d. However, apart from contamination of parenteral nutrition fluids with Mn (Jetton et al. 1976; Hankins et al. 1979; Phillips \& Garnys, 1981; Kurkus et al. 1984) the additional supplementation of Mn from commercial trace element ampoules (e.g. Adamel, Kabi Vitrum) may provide an additional 40 $\mu \mathrm{mol} / \mathrm{d}$, which is about half the normal oral intake. In patients on long-term parenteral nutrition the plasma $\mathrm{Mn}$ concentration is related to the quantity of added $\mathrm{Mn}$; the mean value for those receiving $20 \mu \mathrm{mol} / \mathrm{d}$ is greater than that for those receiving $<20 \mu \mathrm{mol} / \mathrm{d}$. The highest plasma levels, which may be up to tenfold greater than the upper limit of 
normal, occur in patients receiving the highest supplemental dose (about $40 \mu \mathrm{mol} / \mathrm{d}$ ), as reported by Shenkin et al. (1986). High levels are particularly likely to occur in patients with hepatobiliary disease, since $\mathrm{Mn}$ is mainly excreted in bile. If excessive $\mathrm{Mn}$ is infused over prolonged periods of time, possible toxicity from an overload syndrome might be anticipated, by analogy with the chronic Fe overload syndrome.

The first report of $\mathrm{Mn}$ toxicity from excess parenteral intake was that of Couper (1837). This did not involve intravenous administration of $\mathrm{Mn}$ but its inhalation by subjects working in Mn mines. Several subsequent reports confirmed and extended the information about Mn toxicity (Mena et al. 1967; Cotzias et al. 1968; Mena, 1981). In Chile, where $\mathrm{Mn}$ was actively mined, the symptoms were referred to as 'locura manganica', or 'manganic madness'. They consisted of behavioural and psychomotor symptoms (Mena et al. 1967; Mena, 1981), including a type of Parkinson's disease which is normally associated with damage to the basal ganglia in the brain.

Recent studies have shown that administration of excess Mn to monkeys, either by inhalation or intravenously, leads to abnormal magnetic resonance imaging (MRI) brain scans (Newland et al. 1989). The abnormalities were particularly prominent in the region of the basal ganglia, which had been shown previously to be depleted of dopamine and serotonin as a result of excess Mn administration (Bird et al. 1984). The monkeys also exhibited behavioural abnormalities with the higher cumulative doses. Prospective studies in patients on long-term parenteral nutrition (with a supplemental Mn intake of only about $6 \mu \mathrm{mol} / \mathrm{d}$ and an uncertain additional contamination of parenteral nutrition solutions) have also implicated $\mathrm{Mn}$ in an overload syndrome. In one prospective study of nine patients, five of whom had neurological symptoms (either due to the underlying disease, or to other factors such as possible Mn toxicity), striking abnormalities due to the presence of a paramagnetic substance were obtained from the basal ganglia, especially the globus pallidus, and subthalamic nuclei (Mirowitz et al. 1991; Mirowitz \& Westrich, 1992). One patient who had the typical abnormalities on the MRI scans, after receiving parenteral nutrition for 3 years, showed resolution of the abnormalities during the subsequent year when $\mathrm{Mn}$ was removed from the regimen whilst the other constituents remained unaltered (Mirowitz \& Westrich, 1992). Abnormalities in the basal ganglia have been demonstrated in MRI scans in patients with liver disease. Since $\mathrm{Mn}$ is almost exclusively excreted in bile, it is possible that some of the abnormalities may be due to $\mathrm{Mn}$ (Inoue et al. 1991). These observations as well as others relating to other trace elements (e.g. Al toxicity in renal dialysis patients) emphasize the potential problems of bypassing the gut, and the need to have strict and sound regulatory processes that prevent trace element mixtures intended for intravenous nutrition from becoming available commercially.

\section{CONSEQUENCES OF CONTINUOUS 24 H FEEDING}

The common practice of infusing nutrients continuously over $24 \mathrm{~h}$, either nasogastrically or intravenously, may have important biochemical and clinical consequences. An insight into these effects can be obtained by considering essential fatty acid deficiency. This was first described in rats by Burr \& Burr (1929), and biochemical evidence for its existence in children was obtained in the 1950 s (Hansen \& Wiese, 1954; Wiese et al. 1954; Adam et al. 1958; Hansen et al. 1958), when diets deficient in essential fatty acids were administered. The first report of essential fatty acid deficiency in adults was that of 
Collins et al. (1971). This report described the biochemical and clinical features in two adults, one of whom had received parenteral nutrition. Several reports followed in subjects given fat-free parenteral nutrition (e.g. Paulsrud et al. 1972), partly as a reaction to the earlier experiences of toxicity from cotton-seed oil and other intravenous fats (Wretlind, 1992).

The development of essential fatty acid deficiency is likely to arise much earlier during continuous fat-free feeding than during intermittent fat-free feeding (Wene et al. 1975). During continuous fat-free feeding the percentage contribution of the essential fatty acid linoleic acid to total fatty acid concentration in various circulating lipid fractions (triacylglycerols, phospholipids, free fatty acids) decreases severalfold within a matter of only a few days to 1 week (Wene et al. 1975). The availability of free non-esterified linoleic acid may decrease even more because the total circulating concentration of non-esterified fatty acids decreases as a consequence of hyperinsulinaemia, which is associated with high-carbohydrate (fat-free) feeding. Apart from the major reduction in the availability of linoleic acid, the other classic biochemical stigmata of essential fatty acid deficiency, including an increase in triene:tetraene, develop within only a few days to 1 week (Wene et al. 1975). However, there is an apparent paradox because a man with about $15 \mathrm{~kg}$ fat has about $1.5 \mathrm{~kg}$ linoleic acid which is sufficient to supply the essential fatty acid needs of the body for about a year. Why then should biochemical evidence of essential fatty acid deficiency occur within 1 week? There is another apparent paradox; the absence of dietary intake during prolonged experimental starvation in man has not resulted in essential fatty acid deficiency.

These observations can be reconciled by considering the availability of fatty acid from adipose tissue. During starvation, adipose tissue releases various fatty acids including essential fatty acids, and their circulating concentration increases (Gray et al. 1991). There is, therefore, no shortage of essential fatty acids during starvation. In contrast, fat-free feeding (high-carbohydrate feeding) suppresses the release of fatty acids by adipose tissue; and if the feeding is continuous, the suppression is also continuous. Therefore, in this situation there is deficiency in the midst of plenty. In the subjects studied by Wene et al. (1975) a single day's starvation after $7 \mathrm{~d}$ fat-free feeding was sufficient to double the percentage contribution of linoleic acid to some circulating lipid fractions (the actual increase of free linoleic acid is likely to be even greater because the circulating concentration of non-esterified fatty acids (NEFA) increases during starvation). Furthermore, when the $1 \mathrm{~d}$ period of starvation was followed by intermittent fat-free feeding, the percentage contribution of linoleic acid to the total fatty acid content of various circulating lipid fractions did not decrease, presumably because adipose tissue was intermittently releasing its fatty acids that were stored as triacylglycerols.

The mode of feeding (continuous instead of intermittent) has potential as a therapeutic strategy in patients with disease. For example, changes in the composition of membrane lipids, produced by feeding diets of specific fatty acid composition, can modify the metabolic response to injury and endotoxin in animals and man (e.g. Cook et al. 1981; Kinsella et al. 1990; Pomposelli et al. 1991; Grimble, 1992), and alter mortality in animal studies (e.g. Mascioli et al. 1989), presumably by mediating prostaglandin and leukotriene synthesis, and modifying the activity of membrane receptors such as the insulin receptor, as suggested by a recent study of insulin resistance in man (Borkman et al. 1993). However, the problem is the time required to achieve changes in the composition of membrane lipids. Intermittent feeding may take more than 2 weeks, or even months, 
to produce major and significant changes in membrane composition. This is because of the large 'buffering' effect of adipose tissue which takes up fatty acids part of the time and releases its own endogenous fatty acids (stored as triacylglycerols) the other part of the time. On the other hand, recent studies suggest that continuous $24 \mathrm{~h}$ feeding can produce major changes in the composition of membrane lipids of animals and man within a few days to 1 week (Adams et al. 1993; Palombo et al. 1993). This means that it may become possible to modify the response to stress by beginning a short period of continuous feeding (using formulas of specific fatty acid composition) before an elective form of stress (e.g. elective surgery), or even after an injury has occurred.

\section{MISSING NUTRIENTS}

The concept that deficiency of nutrients can occur in the midst of plenty is not restricted to adipose tissue. For example, Rudman et al. (1975) provided a high-energy intravenous feeding regimen to depleted patients with and without phosphate. In the presence of phosphate the subjects were in substantial positive $\mathrm{N}$ balance. When phosphate was removed from the feed for a period of $6 \mathrm{~d}$ the $\mathrm{N}$ balance became negative. On reintroduction of the phosphate the $\mathrm{N}$ balance became positive again. During the intermediate period, the phosphate present within lean tissues was not available for synthesis of new tissue, and the circulating phosphate concentration decreased, partly as a result of hyperinsulinaemia, which favours uptake of both glucose and phosphate into cells (Sitrin \& Wood, 1983). Reductions in circulating phosphate concentrations have also been implicated in causing sudden death (Weinsier \& Krumdiek, 1981) from cardiac causes and in adversely affecting skeletal muscle function to the extent that they precipitate respiratory failure, making artificial ventilation necessary (Newman et al. 1977). However, for decades clinicians who have administered peripheral fluids lacking in phosphate have not been troubled by such problems, presumably because lean tissue breakdown releases phosphate and increases its availability. On the other hand during intravenous phosphate-free feeding of malnourished patients, who have marked anabolic potential, important clinical problems may occur, especially when the pharmacist or clinician forgets to add phosphate to those commercial intravenous feeds that lack it.

Another example of how dietary manipulations can affect substrate availability involves amino acids during the feeding-fasting transition (Ozalp et al. 1972). For example, diets lacking in individual essential amino acids such as isoleucine do not result in a significant change in circulating isoleucine concentrations after an overnight fast, presumably because the missing amino acids are released from lean tissues. However, abnormalities become strikingly apparent in the fed state. Although under normal circumstances the concentration of isoleucine increases $30-40 \%$ after a meal, administration of an isoleucine-free meal results in a severalfold reduction in its circulating concentration (Ozalp et al. 1972).

Such observations would seem to have little clinical significance because general purpose commercial amino acid formations include all the essential amino acids. However, in clinical practice the distinction between essential and non-essential amino acids is not always clear. Some of the amino acid solutions used in parenteral nutrition lack tyrosine and cystine/cysteine, partly because of their poor solubility/instability, and partly because of the belief that they can be synthesized in adequate quantities from their precursors (tyrosine from phenylalanine, and cystine from methionine), which are 
included in the amino acid mixtures. Indeed, administration to normal subjects of solutions containing phenylalanine and no tyrosine or methionine and no cystine results in an increase in the plasma concentration of all these amino acids. However, administration of such solutions to some patients with liver disease may result in a marked reduction in the plasma concentration of tyrosine (and cystine) to values below normal, in association with an exaggerated rise in the plasma phenylalanine (and methionine) concentration (Rudman et al. 1981). In this situation there seems to be a metabolic block in the conversion of phenylalanine to tyrosine and possibly methionine to cystine. Thus, when tyrosine plus cystine were added to the parenteral feed of these depleted patients with cirrhosis, the $\mathrm{N}$ balance, which was persistently close to zero before the addition, became markedly positive. It seems that tyrosine and/or cystine could not be synthesized in adequate quantities from their precursor amino acids as in normal subjects and, therefore, they had become conditionally essential.

Arginine is another amino acid that is normally classified as non-essential for man, although in some circumstances it may become conditionally essential. In carnivores it has long been classified as an essential amino acid. Indeed, a single meal lacking in arginine, which is a urea-cycle intermediate, may be sufficient to cause death in cats within 1-4 h (MacDonald \& Rogers, 1984; Anon, 1985; Rogers \& Phang, 1985). This is associated with a rise in blood $\mathrm{NH}_{3}$ concentration which is toxic, decreased excretion of urea which is partly replaced by orotic acid, and low hepatic concentrations of urea-cycle intermediates (arginine, citrulline and ornithine). Administration of arginine, citrulline and ornithine can prevent or correct the metabolic defect and symptoms. Thus, the absence of dietary arginine impairs the activity of the urea cycle and, therefore, results in decreased urea production, whilst the plasma $\mathrm{NH}_{3}$ concentration rises to toxic levels. Some of the excess $\mathrm{NH}_{3}$ is channelled towards synthesis of orotic acid which is excreted in increased quantities.

In the fasting state arginine is available from breakdown of lean tissues, but in the fed state (after an arginine-free meal) it becomes 'trapped' in peripheral lean tissues and, therefore, is unavailable for the urea cycle which operates in the liver. Other urea-cycle intermediates such as ornithine can compensate for this defect, but in the cat the activity of the enzyme responsible for the synthesis of ornithine from glutamate, a process which occurs in the gut, is very much weaker than that in several other mammals (MacDonald \& Rogers, 1984; Anon, 1985; Rogers \& Phang, 1985).

Administration of some commercial amino acid solutions deficient in arginine to some babies (prematurity is more likely to be associated with immature enzyme systems) who could not synthesize sufficient arginine (or other urea-cycle intermediates) endogenously resulted in a biochemical profile similar to that of the cat (Winters et al. 1983). The abnormalities were reversed by adding arginine to the parenteral feed. Since these studies the composition of intravenous feeds has changed to take into consideration the potential problems of arginine deficiency.

\section{PRECURSOR SUBSTRATES}

The absence of arginine in some of the early commercial intravenous amino acid solutions was not due to pharmacological constraints, but to a conceptual problem based on the erroneous belief that arginine can always be synthesized in sufficient quantities by 
the human body to meet requirements. However, for other nutrients there are pharmacological constraints. For example, tyrosine is poorly soluble and glutamine is unstable. Heat sterilization quickly destroys glutamine, which explains why all commercial intravenous amino acid solutions lack free glutamine (Elia, 1992). The amounts of $\mathrm{Ca}$ and phosphate that can be added to parenteral nutrition solutions are also limited because of the potential problems of precipitation of $\mathrm{CaPO}_{4}$, especially in the intravenous feeds of growing babies who have high requirements for these nutrients and who, at the same time, are fluid-restricted because of their clinical condition. These problems may be overcome by administering precursor substrates that are stable, soluble and less likely to interact with other feed constituents. Phosphate has been administered as organic phosphate (glucose phosphate, fructose phosphate, fructose biphosphate, glycerol phosphate; for example, see Hanning et al. 1991) because this does not precipitate with the Ca that is also present in the feed. Once it is within the body it is hydrolysed to yield free phosphate. Indeed, the routine use of such organic phosphate has proved effective. Tyrosine, cystine and glutamine may be given as components of synthetic dipeptides or as acetyl derivatives of amino acids (e.g. glycyl-tyrosine, $n$-acetyl-tyrosine, alanine-cystine, alanine-glutamine, glycyl-glutamine, $n$-acetyl-glutamine) which are hydrolysed within the body to release their constituent amino acids. In this way feeds that were lacking or deficient in specific amino acids may now include them in large quantities. For example, glutamine has become the dominant amino acid in some recent clinical trials involving parenteral nutrition (Ziegler et al. 1993).

\section{NUTRITION OR PHARMACOLOGY?}

The practice of clinical nutrition has introduced unphysiological and unconventional approaches to feeding (e.g. bypassing the gut, continuous instead of intermittent feeding and unusual combinations and quantities of individual nutrients). This raises the question of whether nutritional support should be regarded as a form of pharmacology. Support for this concept comes from the inclusion of drugs and bioactive substances in the nutrition regimen, in an attempt to improve utilization of nutrients and improve tissue structure and function. Some experience has been obtained with human bioactive recombinant proteins that may have general effects (e.g. growth hormone, insulin-like growth factors) or more specific effects (e.g. erythropoietin which stimulates haemoglobin synthesis). Growth hormone and insulin-like growth factors (IGF), either alone or in combination, have been used in an attempt to improve $\mathrm{N}$ balance in a variety of states in which catabolism and/or malnutrition are likely to occur, e.g. low-energy dieting, elective surgery, corticosteroid-induced catabolism, burns, AIDS and chronic obstructive airways disease (Manson \& Wilmore, 1986; Dahn et al. 1988; Snyder et al. 1988; Belcher et al. 1989; Jiang et al. 1989; Horber \& Haymond, 1990; Chwals \& Bistrian, 1991; Pape et al. 1991; Kupfer et al. 1993; Mjaaland et al. 1993). The use of such agents in normal subjects can result in positive $\mathrm{N}$ balances in the face of a negative energy balance (Manson \& Wilmore, 1986; Kupfer et al. 1993), a situation which is very unusual. The link between fat and lean tissue accretion, therefore, can be broken and manipulated. Furthermore, recent reports, which suggest that the use of such agents results in improved muscle strength after surgery (Jiang et al. 1989), improvement in respiratory muscle function in patients with chronic obstructive airways disease (Pape et al. 1991), and improvement in intestinal function in patients with the short bowel syndrome (in this 
case growth hormone in conjunction with glutamine and fibre; Byrne et al. 1992), are of immense clinical interest.

The clinical use of recombinant human erythropoietin emerged from the severe anaemia associated with end-stage renal failure. The commonest cause of this anaemia, especially in the absence of Al toxicity, is lack of erythropoietin, which is produced by the kidney. Since erythropoietin stimulates the impaired erythropoiesis of end-stage renal failure, its administration might be expected to improve the anaemia and result in clinical benefit. There is usually no shortage of available Fe in end-stage renal failure, especially in patients who have had recurrent transfusions, but there is a problem with $\mathrm{Fe}$ utilization as a result of a lack of an erythropoietic stimulus. Several clinical trials with recombinant human erythropoietin have now been undertaken (Winearls et al. 1986; Eschbach et al. 1987; Rao et al. 1993), including a large multicentre study (Eschbach et al. 1989). All these show improvement in haemoglobin and packed cell volume, which may change from about 0.22 to about 35 (Eschbach et al. 1989). The dose of erythropoietin required to produce the same effect in different patients varies (Eschbach et al. 1989; Rao et al. 1993) depending on the extent of myelofibrosis (Rao et al. 1993), which effectively reduces the available space for erythropoiesis. However, one of the benefits of this form of therapy is the major reduction in transfusion requirements. Indeed, it has been estimated that the routine use of erythropoietin in end-stage renal failure will result in a financial saving of 0.5 million units blood/year in the USA. At the same time it will reduce hospitalization, reduce the risk of infection associated with the administration of blood (e.g. HIV) and reduce the risk of Fe overload. As far as the patient is concerned administration of erythropoietin results in improved quality of life (Karnofsky Scale and Nottingham Health Profile, and subjective feelings of activity level and energy level; Eschbach et al. 1989). The results of a study by the Canadian Orthopedic Perioperative Erythropoietin Study Group (1993) in patients undergoing hip replacement suggest that erythropoietin (administered for 1 week before and $4 \mathrm{~d}$ after surgery) can significantly reduce the incidence of postoperative anaemia (46\% v. 23\% with haemoglobin $<80 \mathrm{~g} / \mathrm{l}$ ) and the percentage of patients requiring blood transfusions (26 v. 3). It is clear that there is likely to be a need for large-scale production of recombinant bioactive human substances, so that they will become more readily available for clinical use.

\section{REFERENCES}

Adam, D. J. D., Hansen, A. E. \& Weise, H. F. (1958). Essential fatty acids in infant nutrition. II. Effect of linoleic acid on caloric intake. Journal of Nutrition 86, 555-564.

Adams, S., Dellinger, E. P., Wertz, M. J., Oreskovich, K., Simonowitz, D. \& Johansen, K. (1986). Enteral versus parenteral nutritional support following laparotomy for trauma: a randomised prospective trial. Journal of Trauma 26, 882-891.

Adams, S., Yeh, Y.-Y. \& Jensen, G. L. (1993). Changes in plasma erythrocyte fatty acids in patients fed enteral formulas containing different fats. Journal of Parenteral and Enteral Nutrition 17, 30-34.

Alexander, W. (1990). Nutrition and translocation. Journal of Parenteral and Enteral Nutrition 14, $1705-1745$.

Alverdy, J. C., Aoys, E. \& Moss, G. S. (1988). Total parenteral nutrition promotes bacterial translocation from the gut. Surgery 104, 185-190.

Alverdy, J. C. \& Burke, D. (1992). Total parenteral nutrition: Iatrogenic immunosuppression. Nutrition 8 , 359-365.

Alverdy, J., Chi, H. S. \& Sheldon, G. F. (1985). The effect of parenteral nutrition on gastrointestinal immunity. The importance of enteral stimulation. Annals of Surgery 202, 681-693.

Anon (1985). Intestinal ornithine synthesis from glutamic acid. Nutrition Reviews 43, 119-121. 
Belcher, H. J. C. R., Mercer, D., Judkins, K. C., Shalaby, S., Wise, S., Marks, V. \& Tanner, N. S. B. (1989) Biosynthetic growth hormone in burned patients: a pilot study. Burns 15, 99-107.

Bird, E. D., Anton, A. H. \& Bullock, B. (1984). The effect of manganese inhalation on basal ganglia dopamine concentration in rhesus monkey. Neurotoxicology 1, 59-66.

Boeckman, C. R. \& Krill, C. E. (1970). Bacterial and fungal infections complicating parenteral alimentation in infants and children. Journal of Pediatric Surgery 5, 117-126.

Border, J. R., Hassett, J., LaDuca, J., Seibel, R., Steinberg, S., Mills, B., Losi, P. \& Border, D. (1987). The gut origin septic states in blunt multiple trauma (ISS $=40$ ) in the ICU. Annals of Surgery 206, $427-448$.

Borkman, M., Storlein, L. H., Pan, D. A., Jenkins, A. B., Chisholm, D. J. \& Campbell, L. V. (1993). The relationship between insulin sensitivity and the fatty-acid composition of skeletal-muscle phospholipids. New England Journal of Medicine 328, 238-244.

Burr, G. O. \& Burr, M. D. (1929). A new deficiency disease provided by rigid exclusion of fat from the diet. Journal of Biological Chemistry 82, 345-367.

Byrne, T. A., Morrissey, T., Zeigler, T. R., Gatzen, C., Young, V. L. \& Wilmore, D. W. (1992). Growth hormone, glutamine and fiber enhance adaptation of remnant bowel following massive intestinal resection. Surgical Forum 43, 151-153.

Canadian Orthopedic Perioperative Erythropoietin Study Group (1993). Effectiveness of perioperative recombinant human erythropoietin in elective hip replacement. Lancet 341, 1227-1232.

Chwals, W. J. \& Bistrian, B. R. (1991). Role of exogenous growth hormone and insulin-like growth factor I in malnutrition and acute metabolic stress: a hypothesis. Critical Case Medicine 19, 1317-1322.

Collins, F. D., Sinclair, A. J., Royle, J. P., Coats, D. A., Maynard, A. J. \& Leonard, R. F. (1971). Plasma lipids in human linoleic acid deficiency. Nutrition and Metabolism 13, 150-167.

Cook, J. A., Wise, W. C., Knapp, D. R. \& Halushka, P. V. (1981). Essential fatty acid deficient rats: a new model for evaluating arachidonate metabolism in shock. Advances in Shock Research 6, 93-105.

Cotzias, G. C., Horiuchi, K., Fuenzalida, S. \& Mena, I. (1968). Chronic manganese poisoning. Clearance of tissue manganese concentrations with persistence of the neurological picture. Neurology 18, 376-382.

Couper, J. (1837). On the effects of black oxide of manganese when inhaled into the lung. British Annals of Medicine, Pharmacy, Vital Statistics and General Science 1, 41-42.

Dahn, M. S., Large, M. P. \& Jacobs, L. A. (1988). Insulin-like growth factor production is inhibited in human sepsis. Archives of Surgery 123, 1409-1414.

Deitch, E. A. (1992). Multiple organ failure. Annals of Surgery 216, 117-134.

Deitch, E. A., Weng-Jing, Ma, L., Berg, R. D. \& Specian, R. D. (1990). Protein malnutrition predisposes to inflammatory-induced gut-origin septic state. Annals of Surgery 211, 560-568.

Department of Health (1991). Dietary Reference Values for Food Energy and Nutrients for the United Kingdom. London: H.M. Stationery Office.

Dionigi, R., Dominioni, L., Gnes, F. \& Ballabio, A. (1977). The effects of total parenteral nutrition on immunodepression due to malnutrition. Annals of Surgery 185, 467-474.

Dudrick, S. J., Wilmore, D. W., Vars, H. M. \& Rhoads, J. E. (1968). Can intravenous feeding as the sole means of nutrition support growth in the child and restore weight loss in an adult? An affirmative answer. Annals of Surgery 169, 974-984.

Elia, M. (1990). Artificial nutritional support. Medicine International 82, 3392-3396.

Elia, M. (1992). Glutamine in parenteral nutrition. International Journal of Food Sciences and Nutrition 43, 47-59.

Elia, M. (1993). Artificial nutritional support in clinical practice in Britain. Journal of the Royal College of Physicians 27, 8-15.

Elia, M., Goren, A., Behrens, R., Barber, R. W. \& Neale, G. (1987). Evaluation of mannitol, lactulose and ${ }^{31} \mathrm{Cr}$-labelled ethylenediamine-tetraacetate as markers of intestinal permeability in man. Clinical Science 73, 197-204.

Eschbach, J. W., Abdulhadi, M. H., Browne, J. K., Delano, B. G., Downing, M. R., Egrie, J. C., Evans, R. W., Friedman, E. A., Graber, S. E., Haley, N. R., Korbet, S., Krantz, S. B., Lundin, A. P., Nissenson, A. R., Ogden, D. A., Paganini, E. P., Rader, B., Rutsky, E. A., Stivelman, J., Stone, W. J., Teschan, P., Van Stone, J. C., Van Wyck, D. B., Zuckerman, K. \& Adamson, J. W. (1989). Recombinant human erythropoietin in anemic patients with end-stage renal disease. Results of a phase III multicentre clinical trial. Annals of Internal Medicine 111, 992-1000.

Eschbach, J. W., Egrie, J. C., Downing, M. R., Browne, J. K. \& Adamson, J. W. (1987). Correction of the anemia of end-stage renal disease with recombinant human erythropoietin. Results of a combined phase I and II clinical trials. New England Journal of Medicine 316, 73-78. 
Fong, Y., Marano, M. A., Barber, A., He, W., Moldawer, L. L., Bushman, E. D., Coyle, S. M., Shires, G. T. \& Lowry, S. F. (1989). Total parenteral nutrition and bowel rest modify the metabolic response to endotoxin in humans. Annals of Surgery 210, 449-457.

Fukushima, R., Gianotti, L., Alexander, J. W. \& Pyles, T. (1992). The degree of bacterial translocation is a determinant factor for mortality after burn injury and is improved by prostaglandin analogues. Annals of Surgery 216, 438-445.

Gray, D. S., Takahashi, M., Bauer, M. \& Bray, G. A. (1991). Changes in individual free fatty acids in obese females during fasting and refeeding. International Journal of Obesity 15, 163-168.

Greenberg, D. M., Copp, D. H. \& Cuthbertson, E. M. (1943). Studies in mineral metabolism with the aid of artificial radioactive isotopes. Journal of Biological Chemistry 147, 749-756.

Grimble, R. F. (1992). Dietary manipulation of the inflammatory response. Proceedings of the Nutrition Society 51, 285-294.

Hankins, D. A., Reilla, M. C., Scribner, B. H. \& Babb, A. L. (1979). Whole blood trace element concentrations during total parenteral nutrition. Surgery 76, 674-677.

Hanning, R. M., Atkinson, S. A. \& Whyte, R. K. (1991). Efficacy of calcium glycerophosphate vs conventional mineral salts for total parenteral nutrition in low-birth-weight infants: a randomized controlled clinical trial. American Journal of Clinical Nutrition 54, 905-908.

Hansen, A. E., Haggard, M. E., Boelsche, A. N., Adam, D. J. D. \& Wiese, H. F. (1958). Essential fatty acids in infant nutrition. III. Clinical manifestations of linoleic acid deficiency. Journal of Nutrition 66, $565-576$.

Hansen, A. E. \& Wiese, H. F. (1954). Essential fatty acids and human nutrition. II. Serum level for unsaturated fatty acids in poorly nourished infants and children. Journal of Nutrition 52, 367-374.

Horber, F. F. \& Haymond, M. W. (1990). Human growth hormone prevents protein catabolic side effects of prednisolone in rats. Journal of Clinical Investigation 86, 265-272.

Inoue, E., Hori, S., Narumi, Y., Fujita, M., Kariyama, K., Kadota, T. \& Kurodu, C. (1991) Portal-systemic encephalopathy: presence of basal ganglia lesions with high signal intensity on MR images. Radiology 119, 551-555.

Inoue, S., Epstein, M. D.. Alexander, J. W., Trocki, O., Jacobs, P. \& Gura, P. (1989). Prevention of yeast translocation across the gut by a single enteral feeding after burn injury. Journal of Parenteral and Enteral Nutrition 13, 565-571.

Jetton, M. M.. Sullivan, J. F. \& Burch, R. E. (1976). Trace element contamination of intravenous solutions. Archives of Internal Medicine 136, 782-784

Jiang, Z.-M., He, G.-Z., Zang, S.-Y., Wang, X.-R., Yang, N.-F., Zu, Y. \& Wilmore. D. W. (1989). Low dose growth hormone and hypocaloric nutrition attenuate the protein catabolic response after major operation. Surgery 210, 513-523.

Jones, A. L. (1984). The intestinal immune system: a time for the reaper. Gastroenterology 87, $234-237$.

Kinsella, J. E.. Lokesh, B., Broughton, S. \& Whelan, J. (1990). Dietary polyunsaturated fatty acids and eicosanoids: potential effects on the modulation of inflammatory and immune cells: an overview. Nutrition 6, 24-44.

Kudsk, K. A., Carpenter, G., Petersen, S. \& Sheldon, G. F. (1981). Effect of enteral and parenteral feeding in malnourished rats with E. coli-hemoglobin adjuvant peritonitis. Journal of Surgical Research 13, 105-110.

Kudsk, K., Groce, M. A., Fabian, T. C., Minard, G., Tolley, E. A., Poret, A., Kuhl, M. R. \& Brown, R. O. (1992). Enteral versus parenteral feeding. Annals of Surgery 215, 503-513.

Kudsk, K. A., Stone, J. M., Carpenter, G. \& Sheldon, G. F. (1983). Enteral and parenteral feeding influences mortality after hemoglobin-E. coli peritonitis in normal rats. Journal of Trauma 22, 605-609.

Kupfer, S. R., Underwood, L. E., Baxter, R. C. \& Clemmons, D. R. (1993). Enhancement of the anabolic effects of growth hormone and insulin-like growth factor 1 by use of both agents simultaneously. Journal of Clinical Investigation 91, 391-396.

Kurkus, J., Alcock, N. \& Shils, M. (1984). Manganese content of large volume parenteral solutions and of nutrient additives. Journal of Parenteral and Enteral Nutrition 8, 254-257.

Lowry, S. F. (1990). The route of feeding influences the injury response. Journal of Trauma 30, S10-S15.

Lucas, A., Bloom, R. \& Aynsley-Green, A. (1986). Gut hormones and minimal enteral feeding. Acta Paediatrica Scandinavica 75, 719-723.

McCance, R. A. \& Widdowson, E. M. (1943). Iron excretion and metabolism in man. Nature 152, 326-327.

MacDonald, M. L. \& Rogers, Q. R. (1984). Nutrition of the domestic cat, a mammalian carnivore. Annual Review of Nutrition 4, 521-562.

Manson, J. McK. \& Wilmore, D. W. (1986). Positive nitrogen balance with human growth hormone and hypocaloric intravenous feeding. Surgery 100, 188-197. 
Mascioli, E. A., Iwasa, Y., Trimbo, S., Leader, L. Bistrian, B. R. \& Blackburn, G. L. (1989). Endotoxin challenge after menhaden oil diet: effect on survival of guinea pigs. American Journal of Clinical Nutrition 49, 277-282.

Mena, I. (1981). Trace minerals. In Disorders of Mineral Metabolism, vol. 1, pp. 233-270 [F. Bronner and J. Coburn, editors]. New York: Academic Press.

Mena, I., Marin, O., Fuenzalida, S. \& Cotzias, G. C. (1967). Chronic manganese poisoning. Clinical picture and manganese turnover. Neurology 17, 128-136.

Metchkinoff, E. (1908). The Nature of Man: Studies in Opportunistic Philosophy [P. C. Mitchell, editor]. New York: G. P. Putnams \& Sons.

Mirowitz, S. A. \& Westrich, T. J. (1992). Basal ganglial signal intensity alterations: reversal after discontinuation of parenteral manganese administration. Radiology 185, 535-536.

Mirowitz, S. A., Westrich, T. J. \& Hirsh, J. D. (1991). Hyperintense basal ganglia on T1-weighted images in patients receiving parenteral nutrition. Radiology 181, 117-120.

Mjaaland, M., Unieberg, K., Bjoro, T. \& Revhaug, A. (1993). Growth hormone treatment after abdominal surgery decreased carbohydrate oxidation and increased fat oxidation in patients with total parenteral nutrition. Metabolism 42, 185-190.

Moore, E. E. \& Jones, T. N. (1986). Benefits of immediate jejunostomy feeding after major abdominal trauma - prospective randomised study. Journal of Trauma 26, 874-881.

Moore, E. \& Moore, F. (1991). Immediate enteral nutrition following multisystem trauma: a decade perspective. Journal of the American College of Nutrition 10, 633-648.

Moore, F. A., Feliciano, D. V., Andrassy, R. J., McArdle, A. H., Booth, F. V. McL., Morgenstein-Wagner, T. B., Kellum, J. M., Welling, R. E. \& Moore, E. E. (1992). Early enteral feeding compared with parenteral, reduces post-operative septic complications. The results of a meta analysis. Annals of Surgery 1216, 172-183.

Moulin, G. C. D., Hedley-Whyte, J., Paterson, D. G. \& Lisbon, A. (1982). Aspiration of gastric bacteria in antacid-treated patients: a frequent cause of post-operative colonization of the airway. Lancet $\mathbf{i}, 242-245$.

National Academy of Sciences (1980). Recommended Dietary Allowances, 9 th ed. Washington, DC: National Academy Press.

National Academy of Sciences (1989). Recommended Dietary Allowances, 10th ed. Washington, DC: National Academy Press.

Newland, C. M., Ceckler, T. L., Kordower, J. H. \& Weiss, B. (1989). Visualizing manganese in the primate basal ganglia with magnetic resonance imaging. Experimental Neurology 106, 251-258.

Newman, J. H., Neff, T. A. \& Ziporin, P. (1977). Acute respiratory failure associated with hypophosphatemia. Medical Intelligence 296, 1101-1103.

Ozalp, L., Young, V. R., Nagchaudhuri, J., Tontisirin, K. \& Scrimshaw, N. S. (1972). Plasma amino acid response in young men given diets devoid of single essential amino acids. Journal of Nutrition 102, 1147-1158.

Palombo, J. D., Bistrian, B. R., Fechner, K. D., Blackburn, G. L. \& Forse, R. A. (1993). Rapid incorporation of fish oil or olive oil fatty acids into rat hepatic sinusoidal cell phospholipids after continuous enteral feeding during endotoxaemia. American Joumal of Clinical Nutrition 57, 643-649.

Pape, G. S., Freidman, M., Underwood, L. E. \& Clemmons, D. R. (1991). The effect of growth hormone on weight gain and pulmonary function in patients with chronic obstructive airways lung disease. Chest 99 , 1495-1500.

Parsons, C. L., Mulholland, S. G. \& Anwar, H. (1979). Antibacterial activity of bladder surface mucin duplicated by exogenous glycosaminoglycan (heparin). Infection and Immunity 24, 552-557.

Paulsrud, J. R., Pensler, L., Whitten, C. F., Stewart, S. \& Holman, R. T. (1972). Essential fatty acid deficiency in infants induced by fat-free intravenous feeding. American Journal of Clinical Nutrition 25. 897-904.

Peterson, S. R., Kudsk, K. A., Carpenter, G. \& Sheldon, G. (1981). Malnutrition and immunocompetence: increased mortality following an infectious challenge during hyperalimentation. Journal of Trauma 21, $528-533$

Phillips, G. D. \& Garnys, V. P. (1981). Trace element balance in adults receiving parenteral nutrition: preliminary data. Journal of Parenteral and Enteral Nutrition 5, 11-14.

Pomposelli, J. J., Flores, E. A., Blackburn, G. L., Zeisel, S. H. \& Bistrian, B. R. (1991). Diets enriched with $n-3$ fatty acids ameliorate lactic acidosis by improving endotoxin-induced tissue hypoperfusion in guinea pigs. Annals of Surgery 213, 166-176. 
Rao, D. S., Shih, M.-S. \& Mohini, R. (1993). Effect of serum parathyroid hormone and bone marrow fibrosis on the response to erythropoietin in uremia. New England Journal of Medicine 328, 171-175.

Rogers, Q. R. \& Phang, J. M. (1985). Deficiency of pyrroline-5-carboxylate synthase in the intestinal mucosa of the cat. Journal of Nutrition 115, 146-150.

Rudman, D., Kutner, M., Ansley, J., Jansen, R., Chipponi, J. \& Bain, R. P. (1981). Hypotyrosinemia, hypocystinemia and failure to retain nitrogen during total parenteral nutrition of cirrhotic patients. Gastroenterology 81, 1025-1035.

Rudman, D., Millikan, W. J., Richardson, T. J., Bixler, T. J., Stackhouse, W. J. \& McGarrity, W. C. (1975). Elemental balances during intravenous hyperalimentation of underweight adult subjects. Journal of Clinical Investigation 55, 94-104.

Saito, H., Trocki, O., Alexander, J. W., Kopcha, R., Heyd, T. \& Joffe, S. N. (1987). The effect of route of nutrient administration on the nutritional state, catabolic state, catabolic hormone secretion and gut mucosal integrity after burn injury. Journal of Parenteral and Enteral Nutrition 11, 1-7.

Shenkin, A., Fell, G. S., Halls, D. J., Dunbar, P. M., Holbrook, I. B. \& Irving, M. H. (1986). Essential trace element provision to patients receiving home intravenous nutrition in the United Kingdom. Clinical Nutrition 5, 91-97.

Sitrin. M. D. \& Wood, R. J. (1983). Clinical signs and management of hypophosphataemia. Clinical Consultations in Nutritional Support 3, 1-6.

Snyder, D. K., Clemmons, D. R. \& Underwood, L. E. (1988). Treatment of obese diet-restricted subjects with growth hormone for 11 weeks: effects of anabolism, lipolysis and body composition. Journal of Clinical Endocrinology and Metabolism 67, 54-61.

Troche, G. (1993). Translocation bacterienne: place de la nutrition artificielle. (Bacterial translocation: the role of artificial nutrition.) Nutrition Clinique et Metabolisme 7, 101-110.

Weinsier, R. L. \& Krumdieck, C. L. (1981). Death resulting from overzealous total parenteral nutrition: the refeeding syndrome revisited. American Journal of Clinical Nutrition 34, 393-399.

Wene, J. D., Connor, W. E. \& Besben, L. D. (1975). The development of essential fatty acid deficiency in healthy men fed fat free diets intravenously and orally. Journal of Clinical Investigation 56, 127-134.

Wiese, H. F., Gibbs, R. H. \& Hansen, E. (1954). Essential fatty acids and human nutrition. I. Serum levels for unsaturated fatty acids in healthy children. Journal of Nutrition 52, 355-365.

Winearls, C. G., Pippard, M. J., Downing, M. R., Oliver, D. O., Reid, C. \& Cotes, P. M. (1986). Effect of human erythropoietin derived from recombinant DNA on the anaemia of patients maintained by chronic haemodialysis. Lancet ii, 1175-1177.

Winters, R. W., Heird, W. C. \& Dell, R. B. (1983). Parenteral amino acid nutrition in infants. In Amino Acids, Metabolism and Medical Applications, pp. 327-336 [G. L. Blackburn, J. P. Grant and V. R. Young, editors], Boston, Bristol, London: John Wright PSG Inc.

Wretlind, A. (1992). Recollections of pioneers in nutrition: Landmarks in the development of parenteral nutrition. Journal of the American College of Nutrition 11, 366-373.

Ziegler, T. R., Smith, R. J., Byrne, T. A. \& Wilmore, D. W. (1993). Potential role of glutamine supplementation in nutrition support. Clinical Nutrition 12, Suppl. 1, 582-590. 